\title{
Posting Feedback - a New Strategy in a Developmental Behavioural Pediatric (DBP) Posting in Post Graduate Medical Training in Singapore
}

\author{
Mulay Kalyani ${ }^{1,2}$, Kang Ying-Qi ${ }^{1,2}$, Aoyama Rie ${ }^{1,2}$, Chong Shang-Chee ${ }^{1,2}$, Tung Serena ${ }^{1,2}$, Chan Yiong- \\ Huak $^{3}$, Rajgor Dimple $\mathrm{D}^{1,2}$, and Kiing Jennifer Sie-Hee, FRACP ${ }^{1,2 *}$ \\ ${ }^{1}$ Department of Paediatrics, Yong Loo Lin School of Medicine, National University of Singapore, Singapore \\ ${ }^{2}$ Khoo Teck Puat-National University Children's Medical Institute, National University Health System, \\ Singapore \\ ${ }^{3}$ Yong Loo Lin School of Medicine, National University Health System, Singapore \\ Email: jennifer_kiing@nuhs.edu.sg
}

\begin{abstract}
We aimed to determine if providing mid posting and end posting verbal feedback to residents in their developmental and behavioural pediatric posting would improve their end of posting competency scores and overall satisfaction with the posting. Data of 17 residents were retrospectively reviewed and ACGME Competency scores were compared. The residents experiencing the new training also provided additional feedback about the training. The ACGME competency scores for the residents who were given mid posting feedback were significantly higher than those who experienced the old training program and did not receive mid posting feedback [Mean (SD) 7.34(0.8) vs $6.81(1.3), \mathrm{P}<0.001]$. The residents reported a better understanding of their strengths and weaknesses and felt they had sufficient time to address their training needs after the mid-posting feedback. [Mean (SD) 7.56(1.0) \& 7.67(1.1) respectively]. Mid posting constructive verbal feedback is a simple intervention which can be implemented in any area of resident training.
\end{abstract}

Keywords: Residency training, pediatrics, posting feedback, mid-posting, end of posting.

\section{Introduction}

Postgraduate training programs in various medical specialties offer a structured and standardised training experience to medical graduates pursuing their career with the final goal of obtaining successful accreditation to practice as a specialist. The Resident is a physician who practices medicine usually in a hospital or a clinic under the direct or indirect supervision of an attending physician. Residency training programs are based on these principles to help trainees experience, reflect on and eventually master essential skills in the practice of medicine. This would necessitate exposure to a wide range and sufficient number of patients for residents to acquire essential competencies. Competency is not an achievement but rather a stepping-stone to continued learning even after accreditation(Leach, 2002).

Singapore is a tiny island nation of over five million people. The medical education programme is based on the British model of an undergraduate curriculum at the National University of Singapore (NUS), Yong Loo Lin School of Medicine with postgraduate training taking six years after graduation (Chew and Chee, 2005). With the introduction of two new medical schools (Duke-NUS Medical School, Lee Kong Chian School of Medicine), there has been a shift to the American model of post-graduate training with a focus on Accreditation Council for Graduate Medical Education (ACGME) competencies. This model uses six interrelated domains of competence: Medical knowledge, Practice-based learning and improvement, Patient care and clinical competency, Professionalism, Communication and Interpersonal skills, and Systems-based practice (Batalden, Leach, Swing, Dreyfus, and Dreyfus, 2002). The ACGME training curriculum in postgraduate medicine was introduced to the Department of Paediatrics (NUS) and Khoo Teck Puat-National University Children's Medical Institute, National University Health System (KTP-NUCMI, NUH, NUHS), Singapore in January 2014. 
The pediatric department of the NUHS is one of the two teaching institutions in Singapore offering accredited residency training for post-graduates wishing to specialize in pediatrics. Residents spend 36 months in the department of pediatrics and its subspecialties as part of their training programme and are supervised by qualified pediatricians. As part of this training, all residents spend one month rotating through developmental and behavioural pediatric training (DBP) in the child development unit of NUH. The DBP training post is a predominantly offsite posting in a community based designated child development unit. The unit has a staff strength around 20 including five pediatricians experienced in DBP, child psychologists, allied health therapists and administrative support. Residents are assigned to a senior pediatrician (or supervisor) working in the field of DBP. The supervisor provides a learning schedule and goals for the trainee while being available for teaching and guidance. The schedule that the trainee follows for the DBP rotation includes, running DBP clinics (with a focus on history taking, physical examination and formulation), preschool classroom observations, site visits to community centres, observations of therapy sessions i.e allied health and psychology assessments.

A key role of the supervisor is to provide formative and summative assessments on the resident to ensure that residents are able to achieve core competencies that are appropriate to their stage of training.

The practice in the DBP unit has been to carry out summative assessments of residents at the completion of their one-month DBP rotation. The scores are made available online for the residents to view at the end of the posting. Other teaching units follow a similar practice.

We wished to evaluate the utility of providing direct, face-to-face, verbal feedback to rotating residents at two different time-points, first at the mid point or halfway through the training post and then finally at the end of the posting. We obtained the end of posting scores and feedback (ACGME General Feedback Questionnaire) provided by residents about the quality and utility of the posting, training and feedback.

\section{Methods}

Approval for the study was obtained from the relevant Institutional Review Board (IRB) (NUS- IRB). Being an anonymized retrospective review of data study, the request for consent waiver was approved by the IRB.

\section{$2.1 \quad$ Sample}

Seventeen residents who rotated through the DBP programme in ACGME training over an 18-month period from February 2014 to July 2015 were evaluated. Eight residents (Feb 2014 to October 2014) encountered the old training programme (Group 1) while nine residents (November 2014 to July 2015) experienced the new training strategy with a mid-posting feedback component (Group 2). All residents were posted for the duration of one month in DBP unit. Each month only one resident was posted. No resident rotated through the unit in September 2014.

\section{$2.2 \quad$ Measures}

ACGME competencies checklist (ACC) - comprised the standard scoring template used in ACGME training. The resident is scored in the domains of professionalism, interpersonal skills and communications, patient care and clinical competency, medical knowledge and practice based learning and improvement, system based competency and overall clinical competency. Scores range from $1-9$ with $1-3$ representing (Advanced beginner), $4-6$ (Competent), $7-9$ (Proficient) levels. The scores obtained by Group 1 and Group 2 residents were compared (Table 1)

Table 1. ACGME competencies checklist (ACC) completed for both Group 1 and Group 2

\begin{tabular}{l|l|l|l|l|l|l|l}
\hline Item & Groups & Mean & SD & Minimum & Maximum & Median & p-value \\
\hline E1. Punctuality & Group 1 & 6.63 & 1.69 & 4 & 9 & 6.5 & 0.08 \\
\hline & Group 2 & 7.78 & 0.83 & 6 & 9 & 8 & \\
\hline
\end{tabular}




\begin{tabular}{|c|c|c|c|c|c|c|c|}
\hline E2. Responsibility for tasks & Group 1 & 6.63 & 1.69 & 4 & 9 & 6.5 & 0.052 \\
\hline & Group 2 & 7.89 & 0.60 & 7 & 9 & 8 & \\
\hline \multicolumn{8}{|l|}{ Interpersonal \& Communication Skills } \\
\hline \multirow[t]{2}{*}{$\begin{array}{l}\text { E3. Sensitivity to patient culture and } \\
\text { values }\end{array}$} & Group 1 & 6.75 & 1.39 & 5 & 9 & 7 & 0.148 \\
\hline & Group 2 & 7.56 & 0.73 & 7 & 9 & 7 & \\
\hline \multirow[t]{2}{*}{$\begin{array}{l}\text { E4. Demonstrates empathy and } \\
\text { compassion }\end{array}$} & Group 1 & 6.88 & 1.13 & 6 & 9 & 6.5 & 0.123 \\
\hline & Group 2 & 7.67 & 0.87 & 6 & 9 & 8 & \\
\hline \multirow[t]{2}{*}{$\begin{array}{l}\text { E5. Communicates effectively with } \\
\text { professionals }\end{array}$} & Group 1 & 6.75 & 1.04 & 5 & 8 & 7 & $0.026^{*}$ \\
\hline & Group 2 & 7.78 & 0.67 & 7 & 9 & 8 & \\
\hline \multicolumn{8}{|l|}{ Patient Care and Clinical Competency } \\
\hline \multirow[t]{2}{*}{$\begin{array}{l}\text { E6. Administration of the Brigance Child } \\
\text { Development Screen and Scoring }\end{array}$} & Group 1 & 7.25 & 0.89 & 6 & 9 & 7 & 0.948 \\
\hline & Group 2 & 7.22 & 0.83 & 6 & 8 & 7 & \\
\hline \multirow[t]{2}{*}{$\begin{array}{l}\text { E7. Administration of the M-CHAT } \\
\text { autism screen }\end{array}$} & Group 1 & 7.13 & 1.13 & 6 & 9 & 7 & 0.841 \\
\hline & Group 2 & 7.22 & 0.83 & 6 & 8 & 7 & \\
\hline \multirow[t]{2}{*}{$\begin{array}{l}\text { E8. Assessment of medical write up } \\
\text { including history, exam and discussion }\end{array}$} & Group 1 & 6.75 & 1.49 & 5 & 9 & 6.5 & 1.0 \\
\hline & Group 2 & 6.75 & 0.89 & 6 & 8 & 6.5 & \\
\hline \multirow[t]{2}{*}{$\begin{array}{l}\text { E9. Assessment of cases clerked including } \\
\text { history, exam and discussion }\end{array}$} & Group 1 & 7.00 & 1.20 & 6 & 9 & 6.5 & 0.489 \\
\hline & Group 2 & 7.33 & 0.71 & 6 & 8 & 7 & \\
\hline \multicolumn{8}{|c|}{ Medical Knowledge \& practice Based Learning and Improvement } \\
\hline \multirow[t]{2}{*}{$\begin{array}{l}\text { E10. } 30 \text { min presentation on child } \\
\text { development topic }\end{array}$} & Group 1 & 6.50 & 1.29 & 5 & 8 & 6.5 & 0.242 \\
\hline & Group 2 & 7.33 & 0.82 & 6 & 8 & 7.5 & \\
\hline \multirow[t]{2}{*}{$\begin{array}{l}\text { E11. Applies knowledge in clinical } \\
\text { contexts }\end{array}$} & Group 1 & 6.88 & 1.36 & 5 & 9 & 6.5 & 0.978 \\
\hline & Group 2 & 6.89 & 0.60 & 6 & 8 & 7 & \\
\hline \multicolumn{8}{|l|}{ Systems-based Practice } \\
\hline \multirow[t]{2}{*}{$\begin{array}{l}\text { E12. Integrates clinical care with } \\
\text { community-based resources }\end{array}$} & Group 1 & 6.50 & 1.31 & 5 & 9 & 6.5 & 0.583 \\
\hline & Group 2 & 6.78 & 0.67 & 6 & 8 & 7 & \\
\hline \multirow[t]{2}{*}{$\begin{array}{l}\text { E13. Demonstrates an understanding of } \\
\text { child functioning within contexts of the } \\
\text { child's preschools }\end{array}$} & Group 1 & 6.63 & 1.41 & 5 & 9 & 6.5 & 0.409 \\
\hline & Group 2 & 7.11 & 0.93 & 6 & 8 & 7 & \\
\hline \multicolumn{8}{|l|}{ Overall Clinical Competency } \\
\hline \multirow[t]{2}{*}{ E14. Overall clinical competency } & Group 1 & 6.88 & 1.36 & 5 & 9 & 6.5 & 0.261 \\
\hline & Group 2 & 7.44 & 0.53 & 7 & 8 & 7 & \\
\hline \multicolumn{8}{|c|}{ Comparison of all mean scores from E1 to E14 for the two groups } \\
\hline & Group 1 & 6.81 & 1.26 & 4.00 & 9.00 & 7.00 & $<0.001$ \\
\hline & Group 2 & 7.34 & 0.80 & 6.00 & 9.00 & 7.00 & \\
\hline
\end{tabular}


Mid-post feedback questionnaire (MPFQ): This included four questions (Table 2)

Table 2. Mid-post-feedback questionnaire (MPFQ) completed by Group 2

\begin{tabular}{l|l|l|l|l|l}
\hline & Mean & $\begin{array}{l}\text { Standard } \\
\text { Deviation }\end{array}$ & Minimum & Maximum & Median \\
\hline $\begin{array}{l}\text { MPF1. After the mid-posting feedback, I have a better } \\
\text { understanding on my areas of strengths in developmental } \\
\text { training }\end{array}$ & 7.56 & 1.01 & 5.00 & 8.00 & 8.00 \\
\hline $\begin{array}{l}\text { MPF2. After the mid-posting feedback, I have a better } \\
\text { understanding on my areas of weakness in developmental } \\
\text { training }\end{array}$ & 7.67 & 1.12 & 5.00 & 9.00 & 8.00 \\
\hline $\begin{array}{l}\text { MPF3. I had sufficient time from the mid-posting feedback } \\
\text { session to address my areas of weakness or strength } \\
\text { throughout the rest of the CDU rotation }\end{array}$ & 7.67 & 1.12 & 5.00 & 9.00 & 8.00 \\
\hline $\begin{array}{l}\text { MPF4. The mid posting feedback contained elements } \\
\text { (about myself, my learning style and training) that I think } \\
\text { are applicable even beyond the CDU posting }\end{array}$ & 7.67 & .87 & 6.00 & 9.00 & 8.00 \\
\hline
\end{tabular}

End-of-post feedback questionnaire (EPFQ): This included three questions in relation to the feedback received online (Table 3).

Table 3. End-of-post feedback (EPFQ) completed by Group 2

\begin{tabular}{l|l|l|l|l|l}
\hline & Mean & $\begin{array}{l}\text { Standard } \\
\text { Deviation }\end{array}$ & Minimum & Maximum & Median \\
\hline $\begin{array}{l}\text { EPF1. Reviewing each item (online) on ACGME } \\
\text { competencies checklist helped me better understand my } \\
\text { strengths and weaknesses }\end{array}$ & 7.78 & .44 & 7.00 & 8.00 & 8.00 \\
\hline $\begin{array}{l}\text { EPF2. My supervisor gave written feedback in a positive } \\
\text { way which was helpful to me }\end{array}$ & 8.11 & .93 & 6.00 & 9.00 & 8.00 \\
\hline $\begin{array}{l}\text { EPF3. My preference is for learning my posting evaluation } \\
\text { online without verbal feedback }\end{array}$ & 3.00 & 1.50 & 1.00 & 6.00 & 3.00 \\
\hline
\end{tabular}

ACGME general feedback questionnaire (GFQ): This included 8 questions to evaluate how the residents rated their training experience (Table 4)

Table 4. ACGME general feedback questionnaire (GFQ): completed by Group 2

\begin{tabular}{l|l|l|l|l|l}
\hline & Mean & $\begin{array}{l}\text { Standard } \\
\text { Deviation }\end{array}$ & Minimum & Maximum & Median \\
\hline EP1. Observations with the developmental pediatrician & 8.11 & .78 & 7.00 & 9.00 & 8.00 \\
\hline $\begin{array}{l}\text { EP2. Observation of allied health, social worker and } \\
\text { psychologists }\end{array}$ & 7.67 & 1.41 & 5.00 & 9.00 & 8.00 \\
\hline EP3. Observation of the school aged clinic & 8.22 & .44 & 8.00 & 9.00 & 8.00 \\
\hline $\begin{array}{l}\text { EP4. Assessing new patients and discussions with } \\
\text { supervisors afterwards }\end{array}$ & 8.56 & .53 & 8.00 & 9.00 & 9.00 \\
\hline $\begin{array}{l}\text { EP5. Preschool observation with write ups of selected } \\
\text { children }\end{array}$ & 7.78 & .83 & 7.00 & 9.00 & 8.00 \\
\hline $\begin{array}{l}\text { EP6. Community visits (i.e preschool centres, early } \\
\text { intervention centres) }\end{array}$ & 7.71 & 1.38 & 5.00 & 9.00 & 8.00 \\
\hline $\begin{array}{l}\text { EP7. Developmental teaching on a Thursday afternoon } \\
\text { EP8. Visit to community resource }\end{array}$ & 6.33 & 2.50 & .00 & 8.00 & 7.00 \\
\hline
\end{tabular}


Resident responses yielded a strengths and difficulties profile. Responses were scored along a Likert scale of $1-9$ with 1 indicating 'not at all' and 9 indicating 'very much so'.

Both, Group 1 and Group 2 Residents were scored on the ACGME competencies checklist and scores were compared. Additionally, Group 2 Residents also completed the MPFQ, EPFQ and GFQ.

\subsection{Procedure}

The mid-posting feedback exercise was a face-to-face session with the assigned supervisor where a strengths and difficulties approach was used to profile the residents' learning and working style. Feedback was provided using a constructive and positive approach. At the end of the posting, the assigned supervisor assessed the residents using the resident posting evaluation form (ACC), with inputs from four other pediatricians in the child development unit.

Group 2 residents had at least two weeks to address the issues and reflect upon their training needs and strengths after the mid-posting feedback session. They were then given verbal feedback again at the end of their posting on how they had improved and what areas needed attention. They were also informed of their final ACC scores. They could subsequently access their ACC scores online.

Group 1 residents who experienced the old training programme were neither given mid posting feedback nor were informed verbally about their ACC scores. They had to access their scores online after the end of posting to find out how they had performed.

The responses obtained from the individual residents were anonymized for the purposes of data collection and analysis. Data was stored ensuring full confidentiality in a single password protected database.

All statistical analyses were performed using SPSS 23.0 with statistical significance set at p $<0.05$. Basic descriptives for the numerical responses were presented as mean (sd), range \& median. Comparisons on the numerical responses between the 2 groups of students were performed using 2 Sample $\mathrm{T}$ test when normality and homogeneity assumptions were satisfied otherwise Mann Whitney U was used.

\section{$3 \quad$ Results}

The data of all the 17 residents (100\%) who rotated through the DBP programme in ACGME (Group1=8 and Group 2=9) were analyzed. There was a significant difference in the residence scores in the core competencies of professionalism and interpersonal and communication skills (E5) between the two groups $(\mathrm{P}=0.026)$ with higher scores obtained by the Group 2 residents. The punctuality (E1) and responsibility of tasks (E2) trended to significant difference $(\mathrm{P}=0.09$ and $\mathrm{P}=0.05$ respectively). However, there was least difference observed in the core competencies of medical knowledge, practice based learning and systems based practice. On comparison of all the scores from E1 to E14, comparing the mean response of E1 to E14 for all the subjects showed significant difference in the two groups with the Group 2 obtaining higher scores [Mean (SD) 7.34(0.8) vs 6.81(1.3), $\mathrm{P}<0.001$ ](Table 1).

Mid-posting feedback was, in general reviewed positively by the residents (Table 2). Not only did they report that they had a better understanding of their strengths (mean 7.56; SD 1.01) but they also felt that their understanding regarding areas of weakness had improved (mean 7.67; SD 1.12). Further, they were satisfied that the time period available to them after the mid-post feedback was sufficient enough to consolidate their strengths and improve upon their weaknesses (mean 7.67; SD 1.12). Additionally, the residents also perceived that the mid post feedback generally equipped them with concepts that could also be put to use beyond the DBP post in other aspects/posts relevant to their training.

The residents indicated a low preference on getting their scores online without feedback (mean 3.0; SD 1.5) opting for a verbal feedback system, as they felt verbal feedback was positive and helpful (mean 8.11; SD0.9) (Table 3).

Overall, the residents reported being satisfied with the new training initiative (Table 4).

\section{Discussion}

Timely, regular and constructive feedback plays a pivotal role in medical education as it has always 
been with other forms of apprenticeship-based training (Hewson and Little, 1998). It is also well recognized as a catalyst that can improve performance in business and industry. Feedback and its effect in improving overall performance is brought about by concerted effort and needs to be sustained. Achievement of sustained core competencies, meeting stipulated standards and creating achievable objectives is the aim of the feedback process. However, it is well recognized that giving feedback and willfully incorporating it into the trainer or teachers' way of mentoring and training is not easy in actual practice with reluctance seen often on part of the trainer and defensiveness seen in the trainee.

In our study, under the old scheme (Group 1 residents), everyone received online feedback at the end of his or her training post. In a survey of residents' perceptions of the evaluation process at a large academic medical centre by Isaacson (Isaacson, Posk, Litaker, and Halperin, 1995), only 8\% of residents reported that they were "very satisfied" with standard end of training post written feedback. Eighty percent of the residents in this survey received no feedback or very infrequent feedback. In the same study, $17 \%$ of the residents reported "never" or "infrequently" receiving reinforcing feedback (Isaacson, Posk, Litaker, and Halperin, 1995).

Similar to the above study, residents in our study felt dissatisfied with the stand-alone end of posting feedback. In particular, their preference was to have a verbal, dedicated feedback session as compared to just receiving it on-line. The face-to face, verbal, mid-post feedback session, was preferred by the residents. This was reflected in their posting feedback scores, which were significantly and consistently high across all domains.

In our study, group 2 residents reported better understanding of their strengths and weaknesses, which enabled them to address these areas, with enough time on their hands. This helped them to bring about self-directed change leading to improved performance, which translated in better ACGME competency scores. More importantly, they felt that this feedback process could be put to use in any other educational setting, such as in their subsequent postgraduate training posts.

Of interest, mid posting feedback resulted in greatest improvements in professionalism and interpersonal and communication skills and least change in medical knowledge and systems based practice. This may relate to feedback about punctuality and responsibility being more amenable to improvement in a short term one month posting. Improvements in medical knowledge and systems based practice are perhaps more likely to be evident over a longer period of observation and training.

Mid-post feedback is part of the formative assessment process that can provide a framework to guide the trainees, motivate them and reinforce their confidence. This could pave the way to achieve the desired educational objectives (Ben-David, 2000). End-of-post assessments tend to be summative exercises, which may not be ideal when looked at from the training point of view. There is also evidence that it could be counter-productive and act as a barrier to effective learning (Sullivan, 2005). They may also not be motivational in nature and fail to provide the impetus for self-directed learning (Schuwirth and van der Vleuten, 2004).

Studies on adult learning have consistently shown that learners welcome and appreciate constructive feedback (Knowles, 1980). This is particularly so when it directly relates to their performance, as most of them are willing to strive to achieve their learning objectives.

Our study is a small pilot study and has its limitations in terms of its retrospective design and small sample size. Also, the manner in which mid posting feedback was given was not standardized or recorded but left to the expertise of the attending supervisor. However, although standardization of the mid posting feedback was not formally put in place, it primarily involved the supervisor spending up to 30 minutes with the candidate. During this in-person discussion, the supervisor used a constructive approach to not only elaborate on the areas for improvement of the resident but also the strengths of the resident. The supervisor then suggested a few interventions to improve the weaknesses such as spending more time on target areas/procedures. Although supervisors did not receive a formal, standardized training in providing feedback, they are all accredited in a Brazelton Touchpoints (Brazelton, 1992) approach to speaking with families and they used this approach to support the resident. The Brazelton Touchpoints approach is an approach of being supportive with the individuals, which helps to strengthen relationships and empower them. The supervisors were also not blinded to the two training strategies as they were part of the team of doctors who were delivering the new training programme. However, since the study involved evaluation of the already collected data, we presume minimal bias from the supervisor perspective to favour any of the strategy. 
The study is also limited by the fact that the Group 1 residents did not complete the EPFQ and GFQ measures which would have provided additional information on resident perspectives for comparison. However, these are not routinely administered questionnaires and thus the Group 1 residents did not receive it. At the same time, in order to understand how well the new training strategy is received by the residents, Group 2 residents provided their perspective of the new strategy through these questionnaires.

Further large-scale observational studies with methodological improvements are necessary to see if this regular, constructive feedback to the residents can translate into better clinical knowledge gained and better care delivery to patients.

\section{Conclusion}

Our study shows that constructive, on-going feedback in Medical Residency training can be a very useful exercise with benefits for both the trainees and supervisors. Timely and appropriate feedback is a part of continuing professional development and translates into improved teaching related outcomes. Mid posting constructive verbal feedback is a simple intervention, which can be implemented in any area of resident training. It allows residents to reflect on their areas of strengths and difficulties and is rated positively.

\section{References}

1. Leach D. (2002), "Competence is a habit," JAMA, vol. 287, no. 2, 243-244.

2. Chew C, Chee Y. (2005), "Postgraduate medical education and specialist training in Singapore," Ann Acad Med Singapore, vol. 34, no. 6, 182C-189C.

3. Batalden P, Leach D, Swing S, Dreyfus H, Dreyfus S. (2002), "General competencies and accreditation in graduate medical education," Health affairs (Project Hope),vol. 21, no.5, 103-111.

4. Hewson MG, Little ML. (1998), "Giving Feedback in Medical Education: Verification of Recommended Techniques," J Gen Intern Med, vol. 13, no. 2, 111-116.

5. Isaacson J, Posk L, Litaker D, Halperin A. (1995), "Resident perception of the evaluation process," J Gen Intern Med, vol. 10, (4 suppl), S89.

6. Ben-David M. (2000), "The role of assessment in expanding professional horizons," Med Teach, vol. 22, no. 5, 472-477.

7. Sullivan W. (2005), "Work and Integrity: the Crisis and Promise of Professionalism in America," (Jossey-Boss, San Francisco, CA).

8. Schuwirth L, van der Vleuten C. (2004), "Merging views on assessment," Med Educ, vol. 38, no. 12,1208-1210.

9. Knowles M. (1980), "The Modern Practice of Adult Education," 2. vyd. San Francisco, Prentice Hall.

10.Brazelton, T.B. (1992), "Touchpoints: Your Child's emotional and Behavioral Development," Reading, MA: Addison-Wesley. 